\title{
COOPERAÇÃO E DESENVOLVIMENTO HUMANO NA ÁREA DA SAÚDE: UMA EXPERIÊNCIA NA GUINÉ-BISSAU ${ }^{1}$
}

\author{
Paulo Salgado ${ }^{2}$ \\ Paulo Almeida Pereira ${ }^{3}$
}

\begin{abstract}
Resumo: A presente reflexão resulta das experiências vivenciadas e enquadradas em dois projetos na área da saúde na República da Guiné-Bissau (RGB): do Banco Mundial (BM) - "Curso de Formação Pós-Graduada de Médicos" - de 1997 a 2006; e do Banco Africano de Desenvolvimento (BAD) - "Reorganização e Gestão do Hospital Nacional Simão Mendes".

Apresenta-se uma breve descrição dos dois projetos, realçando-se a importância da organização, planeamento e gestão em saúde no contexto de elevada escassez num país africano da África Subsariana: o Hospital Nacional Simão Mendes (HNSM), de Bissau. Tratou-se de definir estratégias em colaboração intima com os atores locais que permitissem uma reorientação da atividade hospitalar em diversos domínios, designadamente, formação de quadros, desenvolvimento profissional, afetação de recursos, sistema de informação, apoio logístico e envolvimento dos diversos stakeholders.

$O$ texto analisa as diversas aprendizagens profissionais e a projeção do conhecimento para reflexão na ação: (i) a problemática da cooperação e sua ligação aos direitos humanos; (ii) os recursos humanos como fator de desenvolvimento no contexto africano; e (iii) saúde em rede como solução adaptável à realidade dos países em desenvolvimento.

As conclusões atêm-se às matérias que consideramos prioritárias para uma cooperação baseada na ética, na reciprocidade de direitos
\end{abstract}

${ }^{1}$ Constitui uma súmula, devidamente atualizada e revista, do Relatório Reflexivo elaborado no âmbito do Mestrado em Gestão - Especialização em Gestão e Administração de Unidades de Saúde, realizado na Universidade Católica Portuguesa, Departamento de Economia, Gestão e Ciências Sociais, e cuja discussão teve lugar em maio de 2014.

2 Mestre em Gestão, especialização em Gestão e Administração de Unidades de Saúde, Departamento de Economia, Gestão e Ciências Sociais, da Universidade Católica Portuguesa. E-mail: paulocsalgado@gmail.com

3 Prof. Auxiliar - Departamento de Economia, Gestão e Ciências Sociais da Universidade Católica Portuguesa. E-mail: ppereira@crb.ucp.pt 
entre os Estados e na dignidade dos povos, em que os recursos humanos e o estabelecimento de redes na atenção à saúde são fundamentais, como fator de desenvolvimento humano.

Palavras-chave: organização, gestão, formação, cooperação, desenvolvimento.

\title{
Title: COOPERATION AND HUMAN DEVELOPMENT IN THE HEALTH AREA: AN EXPERIENCE IN GUINEA-BISSAU
}

\begin{abstract}
The present reflection is a result of experiences within the framework of two projects in the health sector in the Republic of Guinea-Bissau (RGB): "Postgraduate Training Course for Doctors" - 1997-2006, supported by the World Bank (WB); and "Reorganization and Management of Simão Mendes National Hospital ", coordinated by the African Development Bank (AfDB) -.

$A$ brief description of the two projects is presented, highlighting the importance of organization, planning and management in health within the context of very limited resources in a Sub-Saharan African country: the Simão Mendes National Hospital (HNSM), Bissau. Strategies to reorganize several areas of hospital activity were redefined in close collaboration with local groups. A particular focus was given to management training, professional development, resource allocation, information systems, logistics support and involvement of several stakeholders. This paper analyses the various professional apprenticeships and how knowledge can be used as a reflection for action: (i) the issues associated with cooperation initiatives and human rights; (ii) human resources as a factor for development in the African context; and (iii) health networks as solutions suitable for adaptation to the reality of developing countries. Our conclusions focus on issues we consider essential for cooperation initiatives based on ethics, reciprocity of rights between states and the dignity of its people, in which human resources and networking in healthcare are a key factor for human development.
\end{abstract}

Keywords: organization, management, training, cooperation, development 


\section{INTRODUÇÃO}

Citando um excerto do poeta guineense, António Lopes Sabino:

«...Exorcizo o paludismo apeio a poliomielite amputo a desgraça encho a taça de ternura e fica a graça da criança florescendo a vida» In "Tecto do Silêncio", da Coletânea "A Criança na Poesia Moderna Guineense"

O panorama da saúde em África tem sido objeto de várias reflexões. Merece referência o documento "Investir na Saúde é Investir no Desenvolvimento Económico", relembrando fatores que contribuem para o lento progresso registado atualmente na realização dos Objetivos de Desenvolvimento do Milénio (ODM):

«Segundo o Relatório Mundial de Saúde da OMS para 2010, vários fatores contribuem para o lento progresso registado atualmente na realização dos ODM: falta de recursos financeiros, má governação e [falta] de responsabilização; infraestruturas subdesenvolvidas; débeis sistemas de saúde, a falta de enfoque sobre resultados, harmonização e alinhamento da ajuda. Também a instabilidade política e as catástrofes naturais. As principais fontes de ineficiência são bem conhecidas e podem incluir, ao nível nacional, a débil definição da estratégia que leva à atribuição inadequada de recursos e opções de financiamento; o inadequado processo de aquisição, gestão e utilização de medicamentos; a inadequada combinação de pessoal aliada à falta de incentivos ao desempenho. A desigualdade no acesso aos cuidados de saúde contribui igualmente para a ineficiência do sector da saúde, o que leva a que a classe rica beneficie mais dos serviços de saúde subsidiados pelo estado. Estes serviços são frequentemente inacessíveis aos mais desfavorecidos, cujas despesas diretas com a saúde são enormes e geralmente representam mais de metade das despesas totais do sector da saúde de um país.» (Conselho Económico e Social das Nações, 2011: 5).

No que respeita à República da Guiné-Bissau (RGB), o Quadro I ${ }^{4}$ ilustra bem o panorama socioeconómico.

Como se repara, continuam a ser preocupantes as taxas de mortalidade infantil e de mortalidade materna - algo que contradiz os Objetivos de Desenvolvimento do Milénio.

\footnotetext{
${ }^{4} \mathrm{Na}$ verdade, pouco se alterou desde 1996 até à presente data.
} 


\section{Quadro I:}

Caraterização geral da RGB

\begin{tabular}{|l|c|}
\hline \multicolumn{1}{|c|}{ Indicadores } & Valores \\
\hline População Total (milhões) & 1,6 \\
\hline População Urbana (\% do total) & 44,6 \\
\hline Idade mediana (anos) [2010] & 19 \\
\hline Taxa de dependência & $79,7 \%$ \\
\hline Taxa de crescimento anual da população & $2,1 \%$ \\
\hline Taxa de fertilidade (nascimentos por mulher) & 4,9 \\
\hline Taxa de fertilidade adolescente (\%00 dos 15 aos 19 anos) & 96,2 \\
\hline Taxa de mortalidade materna (número por 100 000 nados-vivos) & 790 \\
\hline Taxa de mortalidade infantil- lactentes (\%00) & 92 \\
\hline Taxa de mortalidade infantil- <5 anos (\%00) & 150 \\
\hline Esperança de vida ao nascer (anos) & 48,6 \\
\hline Taxa de Incidência de VIH (15-49 anos) & $2,4 \%$ \\
\hline Taxa de população com menos de 2USD/ dia & 785 \\
\hline PIB per capita (USD, PPS 2005) & 1097 \\
\hline Taxa de crescimento do PIB & 2,1 \\
\hline Rendimento Nacional Bruto (RNB) per capita (constantes 2005 USD) & 1042 \\
\hline Índice de Desenvolvimento Humano (IDH) ajustado à desigualdade & 0,213 \\
\hline Índice de esperança de vida ao nascer ajustado pela desigualdade & 0,224 \\
\hline Índice de educação ajustado pela desigualdade & 0,185 \\
\hline Índice de rendimento ajustado à desigualdade & 0,234 \\
\hline
\end{tabular}
Fontes: UNESCO (2013); PNUD (2011 e 2013)

Por todas estas razões, o Banco Mundial (BM) e o Banco Africano de Desenvolvimento (BAD), os organismos da Organização Mundial de Saúde (OMS), bem como ONG's vocacionadas, têm corporizado ajudas financeiras e humanas de grande monta à RGB. Refira-se que nem sempre estas ajudas conduziram ao crescimento e desenvolvimento, pois que «As vicissitudes internas e os modelos de participação externos deixam-nos preocupados, uma vez que não se eliminaram as situações negativas à adoção do $\mathrm{PAE}^{6} \gg$ (Monteiro, 1996:11-17;36-40).

Ainda recentemente (em 2012), o BAD disponibilizou à RGB um apoio de 8,64 milhões de dólares para projetos no setor da Saúde, incluindo a modernização do Hospital Nacional Simão Mendes (HNSM).

\footnotetext{
${ }^{5}$ Dados de 2002, cf. documento.

${ }^{6}$ Os programas de ajustamento estrutural (PAE), que foram introduzidos nos anos 80 em África, Ásia e América Latina, constituíram um meio para sanar as débeis economias de países em desenvolvimento. Em Bissau, o PAE foi objeto de apreciação pelo Instituto Nacional de Estudos e Pesquisa (INEP).
} 
$\mathrm{O} \mathrm{HNSM}^{7}$ apresentava: (i) estruturas físicas em degradação; (ii) falência organizacional; (iii) generalizada inexistência de regulamentação ou seu incumprimento; (iv) inexistência de um código de ética; (v) falta de integração ou de coordenação interna dos serviços; (vi) débil dimensão pedagógica da formação de dirigentes; (vii) a inexistência de uma carta hospitalar - fatores decisivos para a intervenção do exterior já mencionada: a formação de médicos e a (re)organização e gestão desta Instituição; (viii) grandes deficiências ao nível dos serviços clínicos (em todas as áreas clínicas).

\section{PROJETO DE FORMAÇÃO PÓS-GRADUADA DE MÉDICOS}

Na sequência de Concurso Público Internacional, promovido pelo Governo da República da Guiné-Bissau e financiado pelo BM, foi adjudicado o Projeto de Formação Pós-Graduada de Médicos ao Instituto de Ciências Biomédicas de Abel Salazar (ICBAS) e Hospital Geral de Santo António (HGSA), do Porto, a desenvolver no HNSM, em Bissau, envolvendo as valências de Medicina Interna, Cirurgia Geral, Obstetrícia/ Ginecologia e Pediatria.

O Projeto em causa inseria-se na filosofia definida nos Termos de Referência do Caderno de Encargos constante do Documento "Project du Secteur Social ${ }^{8}$ - services de consultations pour la formation des agents de la santé (FIAS)", cujo objetivo consistia em assistir o Governo [da Guiné-Bissau] com vista a melhorar a capacidade de prestação e qualidade dos cuidados de saúde primários a uma ampla população, nomeadamente aos grupos mais vulneráveis das zonas rurais.

Este Projeto apresentava caraterísticas peculiares: (i) ação de longa duração; (ii) formação em sala e on the job; (iii) deslocação de técnicos ${ }^{9}$ com qualificação muito diferenciada (médicos do HGSA que eram

\footnotetext{
${ }^{7}$ O HNSM é, em termos de assistência diferenciada, o hospital de referência nacional, polivalente e de apoio ao nível dos cuidados primários do Setor Autónomo de Bissau, bem como das regiões de Biombo, Bijagós e norte de Quínara. Serve também as populações carenciadas de assistência hospitalar, ao nível regional.

${ }^{8}$ Projecto do Sector Social (PSS) - Organismo do Ministério da Saúde da RGB com competência para, de acordo com os requisitos do Banco Mundial ser a "agência executora" do Projeto, posteriormente designado Projecto Nacional de Desenvolvimento Social (PNDS).

${ }^{9}$ Dada a natureza do Projeto e a importância que o mesmo assumia no contexto da cooperação, os Ministros da Saúde e da Educação de Portugal conferiram, por despachos ministeriais, a natureza de "reconhecido interesse público" aos profissionais expatriados.
} 
docentes no ICBAS; administradores hospitalares com reconhecida experiência nos PALOP; outros técnicos superiores); (iv) exigência de organização e gestão; (v) envolvimento e empenhamento dos médicos e de outros profissionais; (vi) grande articulação entre as autoridades do Ministério da Saúde e do BM; (vii) ligação entre cuidados de saúde primários e cuidados hospitalares, em obediência a orientações técnicas da OMS.

O Projeto de Formação em referência teve início a 15 de julho de 1997, sendo interrompido por decisão das autoridades guineenses em 17 de julho de 1998, em consequência dos acontecimentos político-militares vividos naquele País. Foi reiniciado em 5 de março de 2001, tendo sido concluído em fevereiro de 2006.

\subsection{Objetivos e Aspetos Gerais}

Os objetivos educacionais gerais eram os seguintes:

a. Promover a saúde em meios hospitalares com interligação entre setor primário e setor hospitalar.

b. Proporcionar a alguns médicos guineenses capacidades técnicocientíficas.

c. Proceder ao enquadramento e envolvimento técnico dos serviços hospitalares, clínicos, de apoio clínico e administrativo.

d. Capacitar o médico para reconhecer os problemas principais de saúde.

e. Criar hábitos de pesquisa de documentação científica.

f. Administrar conhecimentos e habilidades para permitir colaborar com outros profissionais durante a sua prática clínica.

No Quadro II apresentam-se as Fases, duração, elementos constitutivos e Instituições envolvidas no projeto. 


\section{Quadro II:}

Fases, duração, elementos constitutivos e Instituições envolvidas

\begin{tabular}{|c|c|c|c|c|}
\hline Fases & Elementos & Destinatários & $\begin{array}{c}\text { Duração } \\
\text { (meses) }\end{array}$ & $\begin{array}{l}\text { Instituições } \\
\text { envolvidas }\end{array}$ \\
\hline \multirow{3}{*}{$\begin{array}{l}1^{\mathrm{a}} \\
\text { Fase }\end{array}$} & $\begin{array}{l}\text { Gestão de } \\
\text { Instituições } \\
\text { Médicas (GIM), }\end{array}$ & $\begin{array}{l}\text { Médicos e enfermeiros } \\
\text { com funções de gestão } \\
\text { nos serviços clínicos }\end{array}$ & 3 & \multirow{5}{*}{$\begin{array}{l}\text { Faculdade de } \\
\text { Medicina, de } \\
\text { Maputo, Hospital } \\
\text { Américo Boavida, } \\
\text { de Luanda, do KIT } \\
\text { (Holanda) e } \\
\text { outros hospitais } \\
\text { portugueses: } \\
\text { Hospital } \\
\text { Especializado de } \\
\text { Crianças de Maria } \\
\text { Pia, Porto, Centro } \\
\text { Hospitalar de Vila } \\
\text { Nova de Gaia; } \\
\text { Hospital de S. } \\
\text { João, Porto; } \\
\text { Hospital Pedro } \\
\text { Hispano, } \\
\text { Matosinhos. }\end{array}$} \\
\hline & $\begin{array}{l}\text { Preliminário: } \\
\text { sensibilização } \\
\text { para a } \\
\text { Informática, o } \\
\text { Inglês, a consulta } \\
\text { de livros, a } \\
\text { elaboração de } \\
\text { relatórios. }\end{array}$ & Médicos formandos & 3 & \\
\hline & $\begin{array}{l}\text { Fase } \\
\text { Preparatória: } \\
\text { formação de que } \\
\text { coorientaram a } \\
\text { formação }\end{array}$ & $\begin{array}{l}\text { Tutores nacionais } \\
\text { (médicos guineenses } \\
\text { seniores) }\end{array}$ & 1 & \\
\hline $\begin{array}{c}2^{\mathrm{a}} \\
\text { Fase }\end{array}$ & $\begin{array}{l}\text { Internato Geral } \\
\text { Integrado } \\
\text { (Horizontal) }\end{array}$ & $\begin{array}{l}\text { Para o conjunto de } \\
\text { médicos formandos }\end{array}$ & 8 & \\
\hline $\begin{array}{c}3^{\mathbf{a}} \\
\text { Fase }\end{array}$ & $\begin{array}{l}\text { Internato } \\
\text { Vertical }\end{array}$ & $\begin{array}{l}\text { Médicos formandos } \\
\text { divididos por valências }\end{array}$ & 12 & \\
\hline
\end{tabular}

\subsection{Constrangimentos}

Há que assinalar diversos constrangimentos ao longo do processo formativo, designadamente:

a. A dificuldade em estabelecer objetivos e metas claros.

b. A falta de quadros técnico-científicos capazes de mobilizar todos os agentes de saúde dentro do HNSM.

c. Os meios financeiros exíguos.

d. Outras insuficiências graves existentes ao nível de serviços de suporte à atividade clínica e de apoio geral.

\subsection{Benefícios Esperados}

No final do Curso de Pós-Graduação de Médicos, pretendia-se que o Governo Guineense pudesse dispor de médicos com qualificação e domínio de capacidades e competências nas quatro valências referidas, que passariam a constituir um reforço notório na capacidade de resposta do Sistema de Saúde em sede dos cuidados diferenciados, em interligação com os cuidados de saúde primários. 
Tornou-se imperioso criar melhores condições de assistência no HNSM que o ICBAS promoveu, com o apoio da Fundação Calouste Gulbenkian (FCG), do Instituto Português de Apoio ao Desenvolvimento (IPAD), e da Embaixada de Portugal em Bissau, designadamente na formação em gestão hospitalar, na melhoria de alguns serviços de clínica ou de suporte (Maternidade, Pediatria Operatório, Anestesia,) e de suporte à clínica (Patologia Clínica ${ }^{10}$ e Banco de Sangue, Radiologia, Bloco), e ainda a constituição de grupos ou comissões; a resolução de problemas com o fornecimento de água e energia elétrica. Decorreram também ações de formação em serviço nas áreas de enfermagem, de anestesia, de laboratório, serviços de apoio logístico e manutenção.

\subsection{Conclusões}

Sem pretendermos ser exaustivos, enunciamos algumas conclusões:

a. Os resultados obtidos demonstram o interesse e o empenhamento de formadores e formandos, pois a planificação foi feita por profissionais dos dois países.

b. As metodologias adotadas revelaram-se adequadas ao processo de ensino-aprendizagem.

c. A apresentação dos casos clínicos foi genericamente adequada.

d. A colaboração do pessoal hospitalar foi satisfatória.

e. Os meios complementares de diagnóstico e terapêutica revelaram-se insuficientes.

f. A articulação entre os serviços de internamento e as consultas externas e urgência revelou dificuldades com incidência negativa no processo de ensino-aprendizagem.

g. As instalações da biblioteca, salas de aula e alojamento para os formandos provindos das regiões, foram substancialmente melhoradas.

h. O aproveitamento pelos docentes expatriados dos "saberes" dos médicos locais.

i. O surgimento de um verdadeiro espírito de equipa.

Não obstante estes resultados em relação a alguns aspetos do modelo de intervenção, seria necessário um claro e efetivo envolvimento nos problemas estruturais, humanos e sociais da parte dos docentes.

Urge fazer um reparo: o Projeto resultou de um longo percurso mas foi difícil ir além de um 'pacote construído' pela burocracia das organizações internacionais.

10 (i) Criação de um novo Laboratório; (ii) formação dos técnicos de análises clínicas; (iii) elaboração do regulamento do laboratório. 


\section{PROJETO DE REORGANIZAÇÃO E GESTÃO DO HNSM}

\subsection{Caraterização}

Este projeto, financiado pelo $\mathrm{BAD}$, teve como suporte um concurso internacional realizado pelo Ministério da Saúde Pública (MINSAP), tendo sido atribuída a sua realização ao ICBAS. O seu início verificou-se a 3 de outubro de 2005 , conforme contrato estabelecido, terminando a 30 de setembro do mesmo ano.

\section{Quadro III:}

Objetivos, metodologia e resultados esperados

\begin{tabular}{|c|c|}
\hline $\begin{array}{c}\text { Objetivo } \\
\text { Geral }\end{array}$ & $\begin{array}{l}\text { Criar uma estrutura organizacional e funcional que pudesse garantir a } \\
\text { melhoria dos benefícios para os doentes. }\end{array}$ \\
\hline Metodologia & $\begin{array}{l}\text { a. Inquéritos e entrevistas pessoais. } \\
\text { b. Visitas aos serviços. } \\
\text { c. Abordagem modular em sala aula e "on the job". } \\
\text { d. Reuniões bimodais consultores / homólogos. }\end{array}$ \\
\hline $\begin{array}{l}\text { Resultados } \\
\text { esperados }\end{array}$ & $\begin{array}{l}\text { a. Introdução de processos de gestão nos níveis estratégicos, tático e } \\
\text { operacional. } \\
\text { b. Mudança no sistema financeiro e contabilístico. } \\
\text { c. Melhoria do funcionamento global do HNSM. } \\
\text { d. Criação de modelos operacionais a nível de suporte clínico e inventário, } \\
\text { criação de um serviço técnico de procedimentos. } \\
\text { e Mudança do paradigma de verticalização para o paradigma da } \\
\text { cooperação interna. } \\
\text { f. Melhoria a otimização de profissionalização dos funcionários do } \\
\text { Hospital. } \\
\text { g. Rentabilização da capacidade instalada. }\end{array}$ \\
\hline
\end{tabular}

Este modelo de intervenção refletia os principais problemas existentes no hospital. A lógica da intervenção da missão baseava-se (i) na permanência de todos os consultores, (ii) na avaliação diagnóstica inicial e contínua de consultores e homólogos e (ii) na execução das atividades correspondentes. A equipa de assistência técnica era constituída por experientes profissionais como consta do quadro seguinte. 


\section{Quadro IV:}

Equipa de missão, cargos e funções

\begin{tabular}{|c|c|c|}
\hline Nome & Cargo & Funções \\
\hline $\begin{array}{c}\text { Paulo } \\
\text { Salgado }\end{array}$ & $\begin{array}{l}\text { Consultor em } \\
\text { Administração } \\
\text { Hospitalar; GRH; } \\
\text { Apoio à Gestão } \\
\text { Clínica }\end{array}$ & $\begin{array}{l}\text { Identificar e organizar as áreas prioritárias } \\
\text { de intervenção, em estreita colaboração } \\
\text { com a Administração do HNSM }\end{array}$ \\
\hline $\begin{array}{l}\text { Vítor } \\
\text { Seabra }\end{array}$ & $\begin{array}{c}\text { Consultor em } \\
\text { Gestão de Stocks }\end{array}$ & $\begin{array}{l}\text { Acompanhar e avaliar sistematicamente a } \\
\text { qualidade dos serviços, os preços dos atos } \\
\text { e medicamentos, gestão de stocks. }\end{array}$ \\
\hline $\begin{array}{c}\text { Maria da } \\
\text { Conceição } \\
\text { Salgado }\end{array}$ & $\begin{array}{c}\text { Consultor em } \\
\text { Contabilidade e } \\
\text { Sistema Financeiro }\end{array}$ & $\begin{array}{l}\text { Auxiliar a equipa na introdução de um } \\
\text { sistema fiável de contabilidade; } \\
\text { acompanhar a implementação do sistema. }\end{array}$ \\
\hline $\begin{array}{l}\text { João } \\
\text { Faria }\end{array}$ & $\begin{array}{l}\text { Consultor em } \\
\text { Engenharia } \\
\text { Hospitalar }\end{array}$ & $\begin{array}{l}\text { Proceder à definição do material a } \\
\text { adquirir; implementar o sistema de } \\
\text { manutenção baseado na prevenção e } \\
\text { manutenção de rotinas; propor } \\
\text { intervenções externas para resolver os } \\
\text { grandes problemas infraestruturais. }\end{array}$ \\
\hline
\end{tabular}

\subsection{Conclusões}

Relativamente aos quatro universos de intervenção, pode afirmar-se que alguns dos itens foram parcialmente alcançados. Não obstante o esforço evidenciado pelo órgão de gestão do HNSM, não foi possível reunir as condições humanas, financeiras e técnicas que satisfizessem plenamente os objetivos do Projeto. Registe-se, pela positiva, o empenhamento de uma significativa parte dos funcionários e da administração do HNSM e, pela negativa, o enfraquecimento da sua autonomia e consequente desresponsabilização.

Deve ressaltar-se que os projetos levados a cabo pelo BM e BAD, tal como outros - reduzidos no tempo e com envolvimento pouco profundo das entidades do MINSAP e do HNSM - não resolveram cabalmente os problemas de organização e gestão desta importante unidade hospitalar.

Ao HNSM coloca-se um grande desafio: consistirá em transformar-se numa espécie de subsistema de qualidade para constituir um verdadeiro polo aglutinador, uma espécie de "white space"11, em que serão mobilizados todos os "stakeholders" do Setor Autónomo de Bissau: hospital, centros de saúde, ONG's ligadas à saúde, setor de ensino em

11 Este assunto será aprofundado ao abordar as aprendizagens profissionais e a projeção do conhecimento desenvolvidos noutros contextos. 
saúde, escolas, ministérios de natureza social e, ainda, embaixadas e consulados.

\section{APRENDIZAGENS PROFISSIONAIS E PROJEÇÃO DO CONHECIMENTO PARA REFLEXÃO NA AÇÃO}

Qualquer estratégia de saúde fundamenta-se num conjunto de valores e princípios que visam salvaguardar a dignidade humana, a solidariedade e a justiça social, centrando no cidadão e nas comunidades as decisões tecnicamente mais adequadas.

Face à natureza e dimensão das diversas questões suscitadas, e considerando as preocupações fundamentais, bem como a atualização de conhecimentos, são abordados os seguintes aspetos:

A problemática da cooperação: do paradigma da ajuda para o paradigma da cooperação técnica; os direitos humanos em África;

Os recursos humanos (as pessoas) como elemento fundamental no progresso da saúde;

Terceiro: A saúde em rede - uma solução?

\subsection{A Problemática da Cooperação: do Paradigma da Ajuda para o Paradigma da Cooperação Técnica; os Direitos Humanos em África}

$\mathrm{Na}$ Declaração Universal dos Direitos Humanos, humana e historicamente concebido num período reconhecidamente oportuno, estão ínsitas as ideias de promoção de valores como a paz, o respeito pela soberania das nações, a promoção dos direitos da mulher e do homem, na sua plenitude, o desenvolvimento, a valorização das capacidades humanas. Trata-se, aliás, da defesa de um 'mínimo de ética universal'.

Atente-se no seguinte esquema, proposto por Rodrigues (2011: 1315). 


\section{Figura I}

Aspetos relativos à qualidade e dignidade de vida

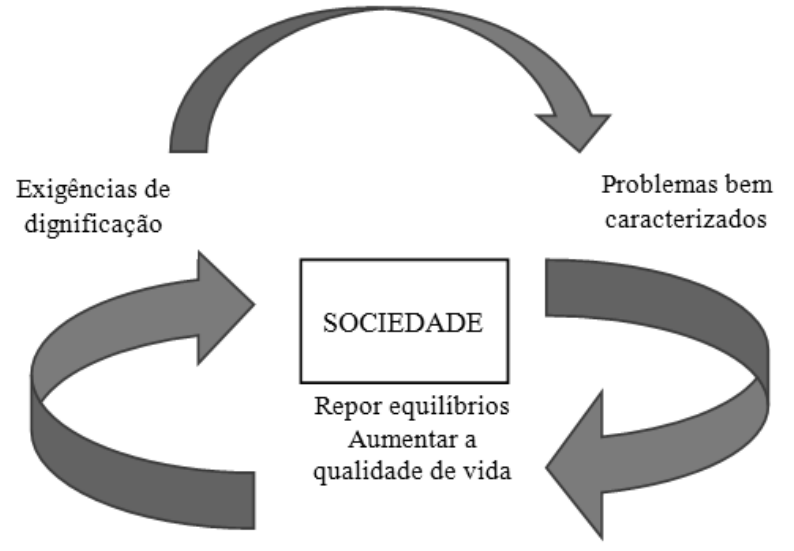

Todavia, os Relatórios da Amnistia Internacional têm evidenciado, em alguns países, o desprezo pelo gozo das liberdades políticas e civis, pela integridade da vida, pela inserção social através da educação e de vida digna, pela igualdade do género e pelos crimes contra o ambiente.

É importante pensar que a saúde é o resultado de diversos fatores, vindo a propósito referir o seguinte:

«Health status is a function of a number of things, but in particularly of public health measures that protect human rights like the rights to primary health care, appropriate and equitable health services, basic immunizations, adequate nutrition, adequate housing, and freedom from violence.» Grodin (2008; 161).

Naturalmente que estas medidas implicam custos e exigem uma forte intervenção das políticas públicas. O mesmo autor lembra que será possível a provisão de recursos, sobretudo em países em vias de desenvolvimento a propósito do designado pacote essencial (mínimo) que compreende, referindo os dados a 1993:

«Expand immunizations, cover HIV prevention, and guarantee prenatal care, delivery care, and family planning services. If implemented, it is estimated that this package would eliminate $32 \%$ of disease burden in low-income countries and $15 \%$ in middle-income countries. The package outline for low-income countries costs $\$ 12$ per capita per year and in middle income countries costs $\$ 22$ per capita per year.» Grodin $(2008 ; 161)$. 
E acrescentava, dubitativamente: «Is this provision of this health care possible? This depends on the commitment of nations and individuals to social justice and respecting the right to health».

De acordo com os elementos de que dispomos ${ }^{12}$, as despesas com saúde variam de acordo com o sistema de saúde aplicado em cada país, das opções políticas (e.g. a \% do PIB destinada à saúde, à educação...), do estado de crescimento das economias e, certamente, do estádio de desenvolvimento dos direitos humanos.

A forma de medir consistentemente a situação sanitária e a sua proteção - por vezes melhorando-a com a introdução de alguns parâmetros de medição - é o Índice de Desenvolvimento Humano que apresenta indicadores e critérios de longevidade, conhecimento, nível de vida digno, participação ou exclusão, permitindo-nos visualizar, a esperança de vida, o conhecimento, a dignidade do nível de vida, entre outros. Chama-se particular atenção para o problema da pobreza, ao qual se vêm associar a exclusão social e a privação de direitos, que envolve um conjunto de aspetos que podem ser cumulativos: etnia, religião, ideologia, orientação sexual, género, incapacidade física, falta de recursos financeiros, doença. Mas inclui também falta de informação e de literacia, limitação na procura de meios de vida, falta de mecanismos de acesso à educação, frágil organização da comunidade, abuso por parte dos que detêm o poder e falta ou falência de democracia participativa.

A cooperação entre estados doadores e estados beneficiários só se torna efetiva se for fundada numa verdadeira vontade e no estabelecimento de confiança. Pretende-se passar do paradigma da "ajuda" ou da "assistência" para o paradigma da "cooperação técnica", assente na reciprocidade de interesses, no respeito entre doadores e beneficiários, na partilha responsável, no envolvimento pessoal de igualdade de oportunidades. Como Bento XVI escrevia na Carta Encíclica Caritas in Veritas $(2009,59)$ :

«Se os sujeitos da cooperação dos países economicamente desenvolvidos não têm em atenção - como às vezes sucede - a identidade cultural, própria e alheia, feita de valores humanos, não podem instaurar algum diálogo profundo com os cidadãos dos países pobres. Se estes, por sua vez, se abrem indiferentemente e sem discernimento a qualquer proposta cultural [ou outra, acrescento: social, sanitária, económica], ficam sem condições para assumir a responsabilidade do seu autêntico desenvolvimento.»

\footnotetext{
${ }^{12}$ A recolha e tratamento de dados no continente africano revela grandes debilidades.
} 
Será, então, correto analisar o verdadeiro sentido da cooperação, face ao que Ruger (2011;32-45) sintetiza:

«Quatro contextos de cooperação:

a. Só cooperamos quando não há forma de o evitar (obrigação).

b. Cooperamos porque temos vantagens em fazê-lo (motivação egoísta).

c. Trabalhar em conjunto porque cada um ganha alguma coisa (reconhecimento de vantagens mútuas).

d. Cooperamos porque nos sentimos associados por um imperativo ético (valores partilhados)»

$\mathrm{Na}$ verdade, pode afirmar-se que, obedecendo mais aos objetivos estratégicos dos países doadores, a ajuda internacional nem sempre contribuiu positivamente para o desenvolvimento humano.

\subsection{Os Recursos Humanos como Elemento Fundamental no Progresso da Saúde}

A gestão de pessoas em saúde começa a ganhar importância crescente, tendo presente as ideias de Chiavenato: "As organizações são compostas de pessoas. $\mathrm{O}$ estudo das pessoas constitui a unidade básica para o estudo das organizações e principalmente da ARH (Administração de Recursos Humanos)" (Chiavenato, 1992, 32) e "O especialista em recursos humanos tem duas alternativas; estudar as pessoas como pessoas (dotadas de caraterísticas de personalidade e individualidade, aspirações, valores, atitudes motivações e objetivos individuais) ou estudar as pessoas como recursos (dotados de habilidades, capacidades, destrezas e conhecimentos necessários para a tarefa organizacional)" (Chiavenato, 1992, 119)

Mais do que a apropriação de uma teoria face a outras, é imperioso dominar os conceitos e aplicá-los de acordo com as circunstâncias e contexto.

De notar que urge desenvolver mecanismos de liderança, uma ideia universal com perfeita oportunidade na realidade africana. É interessante o que está contido no Relatório Mundial da Saúde de 2006:

«Sem uma liderança forte, as políticas nacionais tendem a patinar. A liderança nacional é necessária para iniciar o processo, pressionar por avanços, engajar as partes interessadas (trabalhadores, sociedade civil e governo). O desenvolvimento de habilidades de liderança depende das estruturas de liderança e de capacidades táticas. $\mathrm{O}$ problema é que a maioria das pessoas está inclinada a acreditar que o know-how político é uma qualidade nata e, portanto, não se presta à construção de capacidades.» (OMS, 2006: 127). 
Mesmo em África, onde poderemos observar a tradicional passagem de testemunho do 'soba' ou do 'régulo' para o seu familiar privilegiado, há líderes que não são convencionais, que se 'construíram', habitualmente pela capacidade de influenciação e pelos valores genuínos por que se regem.

Em ambiente africano, a construção de relações de confiança e a capacidade de catalisar são caraterísticas essenciais para a liderança de unidades de saúde em África, já que é imperioso penetrar nas cidades, municípios, comunas, aldeias, enfim nos lugares mais longínquos.

A liderança e a criatividade são elementos determinantes, quer na criação e desenvolvimento de modelos organizacionais, quer na aplicação de medidas capazes de mobilizar os diversos atores da saúde. Damos um exemplo vivido recentemente em Angola: a municipalização da saúde ${ }^{13}$. Neste País, como na RGB, são necessárias liderança e criatividade para organizar os serviços de saúde de proximidade.

\subsubsection{Motivação}

Presentemente, reparamos, empiricamente, que as pessoas não estão apenas interessadas em satisfazer gradualmente as necessidades básicas; por força do "efeito demonstração" procuram satisfazer necessidades superiores sem que as de nível inferior estejam satisfeitas. Bom, estaremos em patamares diversos quando lidamos com a hierarquia de cargos e, por isso, é crível que os fatores promotores de satisfação de Herzberg e de Mclleland (sucesso, poder) expliquem melhor certas situações, em especial ao nível das classes dirigentes. Ao lidar com chefias nas unidades de saúde em África, pode acontecer uma modificação do comportamento organizacional.

No Relatório Mundial de Saúde (OMS, 2006) colocam-se as questões ambientais e higiénicas e de segurança no trabalho que podem provocar níveis elevados de absentismo; de igual modo, é referido que a salários baixos corresponde uma grande rotatividade de pessoas nas instituições de saúde.

Este Relatório refere que os trabalhadores de saúde ficam mais motivados para desempenhar bem as suas tarefas quando as suas instituições e os gestores:

a. Têm um conhecimento profundo da missão e visão e a divulgam.

13 A municipalização da saúde em Angola põe o acento tónico no poder local, procurando reunir as energias das autoridades eleitas, das autoridades tradicionais, dos jovens, das mulheres, dos profissionais de saúde e congregar todos os setores de atividade: ambiente, cultura, economia. 
b. Valorizam o mérito.

c. Ouvem o pessoal.

d. Encorajam o trabalho de equipa.

e. Dão retorno ao bom desempenho e o premeiam.

f. Usam instrumentos sancionatórios justos.

\subsubsection{Desempenho e medição do desempenho}

Para um bom desempenho, aos trabalhadores de saúde é exigido conhecimento atualizado. A formação em sala é um meio útil, mas a aprendizagem em serviço é seguramente um fator mais provável de sucesso na mudança de comportamentos e capacidades tendentes a um desempenho cuidadoso. A este propósito, o Relatório Mundial de Saúde (OMS, 2006) questiona-se sobre que tipo de formação funciona melhor nas unidades de saúde, para concluir que, para uma mudança do desempenho, há mais probabilidades de transferência de conhecimento e habilidades quando o curso das ações de formação é interativo com a maior quantidade possível de experiência prática, de vida real. É imperioso referir dois aspetos fundamentais: (i) as alavancas que influenciam as quatro dimensões do desempenho da força de trabalho em saúde - disponibilidade, competência, capacidade de resposta e produtividade; (ii) o apoio em normas e códigos de conduta.

O sistema de avaliação do desempenho nas organizações de saúde, particularmente em África, deve ser claro, justo e objetivo quanto à conceção, e saber se a estratégia está a ser executada ou não.

Por esta razão, as organizações devem formular o "continuum da estratégia", que se apresenta na figura seguinte (Cruz, 2009: 87):

\section{Figura II}

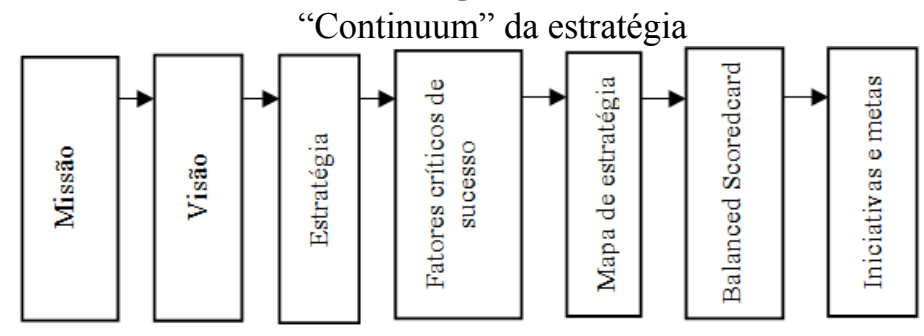

Nas instituições de saúde em África tem perfeita oportunidade a inclusão desta ferramenta, na medida em que não interessa apenas a análise dos indicadores financeiros, mas a medição dos indicadores de efetividade: os resultados alcançados junto das pessoas e das comunidades, como, por exemplo, o sucesso de programas de vacinação, 
o retorno à vida ativa dos doentes curados, a satisfação das empresas que custeiam tratamentos e das seguradoras - como pude observar recentemente, nas atuais atividades que desenvolvo.

\subsection{Governação Clínica}

No conceito de "clinical governance" emergem diversas componentes, claramente identificadas no diagrama seguinte (Campos, 2009: 27).

\section{Figura III}

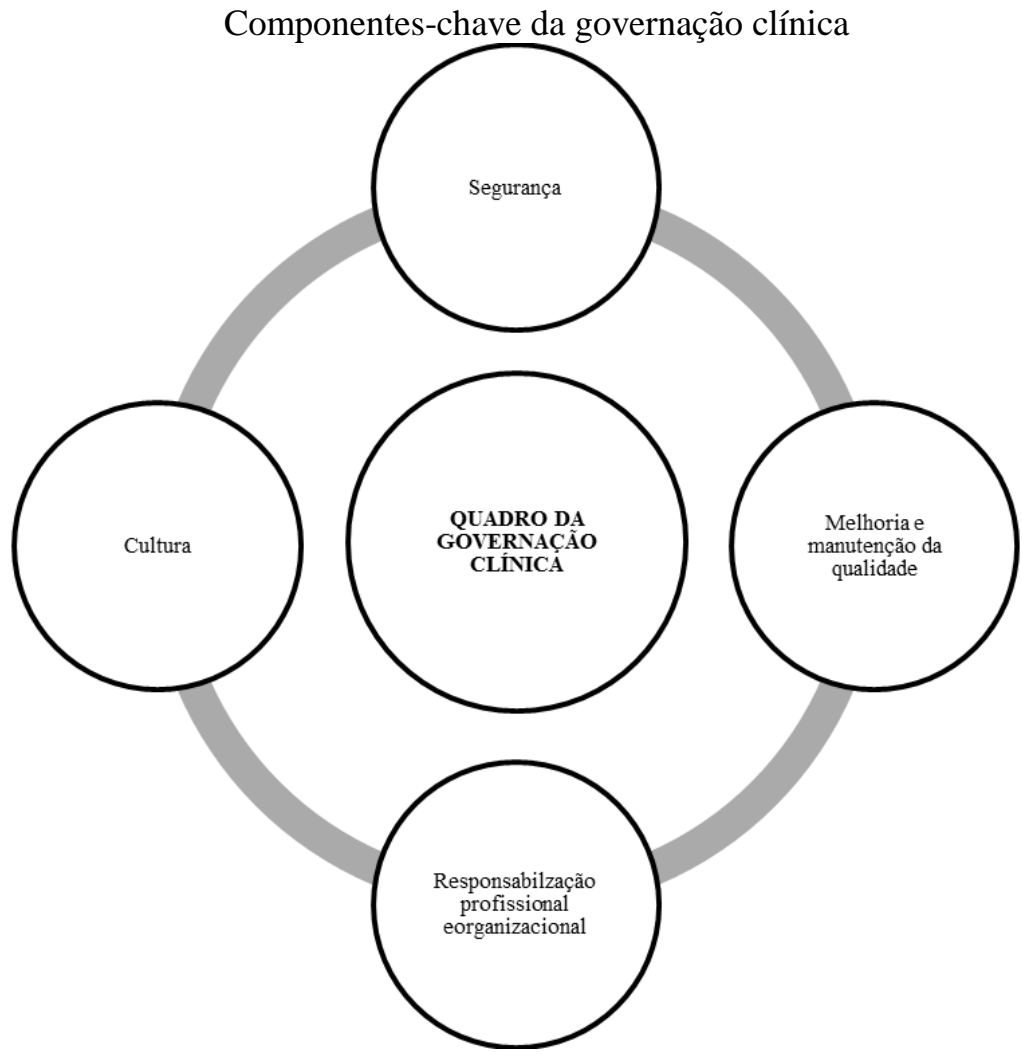

No que respeita à segurança, há múltiplos aspetos a considerar dentro de cada uma das componentes habitualmente referidas: segurança dos doentes, segurança dos profissionais e segurança institucional. Não erramos se dissermos que, hoje, mais do que nunca, mesmo nas sociedades emergentes, a integridade física dos doentes e dos familiares, 
e a integridade dos trabalhadores, de qualquer nível, acaba por recair na alçada da responsabilidade dos dirigentes. A segurança passou a ser um dos indicadores do bom atendimento. Tem de existir uma definição clara de linhas de responsabilidade; há o imperativo de desenvolver bons programas de gestão do risco e de manutenção de equipamentos críticos; há a necessidade de implementar adequados planos de emergência internos.

Questiona-se se à direção do HNSM poderia ser assacada a responsabilidade pela segurança dos doentes e dos seus trabalhadores? Como, se os recursos eram tão escassos? Como, se a organização do trabalho e a deficiência das estruturas físicas pecavam pelas razões mais diversas? Como, se o sistema de abastecimento de bens é incerto, ineficaz e fortemente dependente de doações de terceiros?

Mas já não é assim, onde, como em Angola, existem mecanismos protetores do consumidor, e "pour cause", há uma conscientização crescente dos direitos plasmados na Constituição, e onde a Lei Geral do Trabalho é aplicável nas empresas, incluindo nos hospitais, onde funciona o exercício inspetivo às instituições.

No plano da cultura organizacional, há necessidade de tomar em consideração, por exemplo: (i) a cultura de participação; (ii) as boas práticas de trabalho a todos os níveis; (iii) os compromissos na disseminação dos elementos inovadores; (iv) o trabalho em equipa multidisciplinar e transdisciplinar em todos os níveis; (v) a linguagem organizacional; (vi) os ritos de integração dos novos trabalhadores; (vii) a distribuição de prémios; (viii) a realização de atividades de formação.

No plano da melhoria permanente da qualidade, é importante que seja garantida (Campos, 2009: 23-28): (i) a disponibilidade diária; (ii) a customização de cuidados; (iii) a centralidade do doente; (iv) a necessidade de transparência; (v) a antecipação das necessidades clínicas dos doentes e sua integridade; (vi) a presença de direitos dos doentes (consentimento informado, privacidade, confidencialidade, direito à informação, entre outros); (vii) a cooperação entre todos os profissionais.

É imperioso ter presente que a governação clínica não se confina à atividade clínica envolvendo médicos, enfermeiros, técnicos de diagnóstico, auxiliares de ação clínica - de forma que nos serviços haja o respeito pela garantia de uma prestação com dignidade e em segurança. Estamos plenamente de acordo com a reflexão de Vaz (2009), na medida em que estão envolvidos a gestão de pessoas, o sistema de informação, a gestão de materiais, a gestão da farmácia, as auditorias, a gestão dos transportes e da manutenção, a gestão do arquivo clínico, a gestão financeira, a hotelaria - enfim, a logística, como forma de dar corpo à 
"accountability" institucional e ao reforço do conceito de "equipa de saúde".

\subsection{A Saúde em Rede}

É vasta a revisão bibliográfica sobre redes de atenção à saúde apresentada por Mendes (2007) que salienta: (i) o foco dos serviços de saúde se direcionar numa dada população de um dado território; (ii) a coordenação e integração de um "continuum" de prestação de cuidados; (iii) a possibilidade de abranger as populações mais afastadas; (iv) a melhoria da qualidade do atendimento; (v) a colheita de dados e seu tratamento; (vi) o ganho em economias de escala através do aproveitamento dos recursos. E, o que é muito importante, a verificação do exercício pleno dos direitos humanos.

Constantino Sakellarides, defende ${ }^{14}$ que a integração em rede possibilita uma grande articulação e coordenação de cuidados de saúde, de ensino e de pesquisa. Uma instituição de saúde chamaria a si a responsabilidade de proceder à dinamização da rede, conjugando esforços múltiplos das autoridades locais, das ONG's, de seguradoras e empresas que têm acordos de assistência com as unidades de saúde, o que redundaria num "subsistema de saúde", certamente estribado na Lei «organizing the white space».

${ }^{14}$ Palestra realizada no âmbito do Curso de Formação para gestores de unidades de Saúde (FOGUS), levado a efeito na Clínica sagradas Esperança, Luanda, 2013, pela Escola Nacional de Saúde Pública. 


\section{Figura IV}

Organização em rede

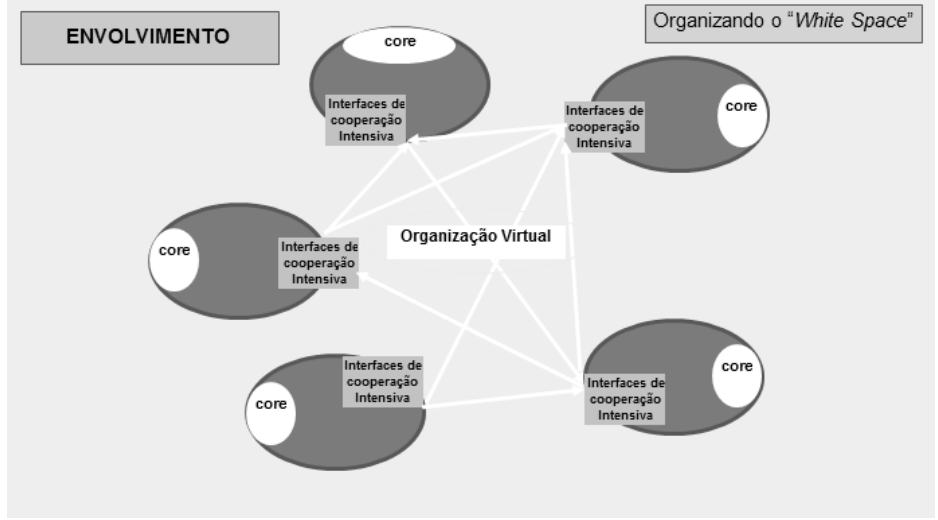

Adaptado de Sakellarides, 2013

A grande dúvida coloca-se, quanto à solução preconizada por Sakellarides, em saber qual a melhor forma de se proceder a esta interligação. Há cinco tipos de rede: em roda, em Y, em cadeia, circular e interligação total (Teixeira, 2012). A opção, do nosso ponto de vista, poderá ser a integração em roda, em que existirá rapidez de comunicação, levando a uma certa centralização e à emergência de liderança forte, sendo reduzida a insatisfação de todos os colaboradores.

Desta forma, quer o HNSM, no Setor Autónomo de Bissau, quer o hospital municipal de um qualquer município de Angola poderiam aproveitar plenamente a tríade abaixo descrita sumariamente por Sakellarides (2013), que se interpenetram e enriquecem.

\section{Figura V}

Do hospital à comunidade

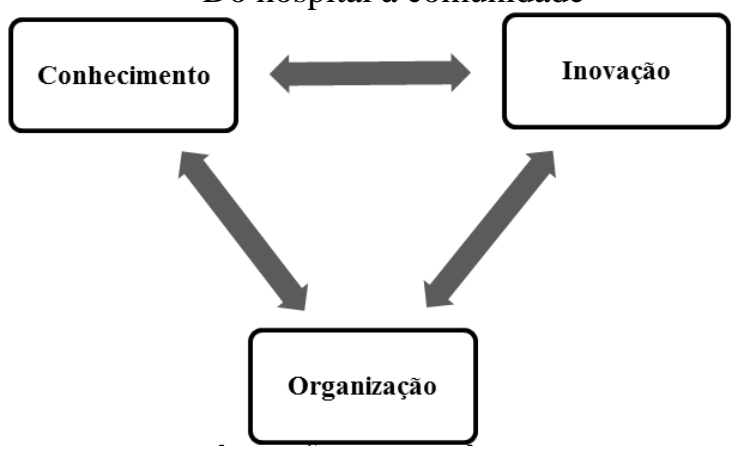


Por esta razão - a de que é a Medicina que deve estar na linha da frente da prevenção da doença, da promoção da saúde, da cura e reabilitação, do ensino e da pesquisa em ambiente hospitalar - a proposta de Sakellarides deve ser ponderada.

Uma nota final, questionando: na rede de atenção à saúde, qual a base negocial que deve assegurar o seu sucesso? Que modelo de intervenção do financiador público? Estão os organismos tecnicamente preparados para assumir objetivos amplos com base num contrato? No plano conceptual, estas duas entidades (Setor Autónomo de Bissau e um Município em Angola), poderiam adotar um suporte contratual que pudesse ser consubstanciado na celebração de contratos entre os diversos agentes prestadores, a partir de um pacote financeiro que fosse atribuído pelo Ministério das Finanças com a intermediação do Ministério da Saúde. Poderia ser um contrato de desempenho contratualizado, como refere Escoval (2010, 7):

«Frequentemente a contratualização não atinge os seus objectivos devido basicamente a falhas na negociação do contrato (informação assimétrica, impreparação do órgão fiscalizador e inexistência de um objectivo agregador), dificuldades na atribuição de autonomia às organizações e problemas conceptuais no acompanhamento e na avaliação do desempenho. Um dos grandes obstáculos à contratualização, apontados pelas diversas experiências, é a insuficiência de conhecimentos dos órgãos responsáveis pelo acompanhamento e fiscalização em preparar e acompanhar esse processo. Evidentemente, a questão da gestão efectiva das bases de conhecimento da organização coloca--se aqui de forma aguda, dado que essa gestão diz respeito não apenas aos conhecimentos técnicos específicos de cada instituição de saúde como também aos conhecimentos tácitos sobre a própria relação contratual.»

Esta nota alerta para o fato de que, não obstante estas dificuldades, a operacionalização de uma rede de atenção à saúde ter de estabelecer regras de compromisso com o financiador.

\section{CONCLUSÕES GERAIS}

Os projetos descritos destinavam-se a estabelecer compromissos educacionais, quer no âmbito da formação, quer no âmbito da organização e gestão de serviços de saúde hospitalares.

Existiu um fio condutor entre os dois projetos, na medida em que foi sentida a necessidade expressa pelo MINSAP, com o empenho do BM e 
do BAD, de criar mecanismos de organização e gestão que foram amplamente detetados $\log$ e durante o Projeto de Formação PósGraduada de Médicos.

São, de seguida, tecidos alguns comentários mais gerais:

a. As caraterísticas da cooperação, como elemento fundamental plasmado em conceitos de grande riqueza, acabam por ser, de alguma forma, transformados em "negócios" que a burocracia alimenta. O preço a pagar pelas "ajudas" é muito elevado. É preciso dar corpo a mecanismos de maior envolvência dos países carenciados, que apresentam grandes vulnerabilidades. A cultura hipertecnológica (as tecnologias de grande ponta) invadiram todo o planeta. Não raramente, temos visto equipamentos de ponta, sofisticados, "depositados" em hospitais de África - sem utilização devida. O techno sapiens terá substituído o homo sapiens sapiens, como refere Lipovetsky (2010:55): «Ao mesmo tempo que exemplifica o poder da razão, a espiral da alta tecnologia não para de segregar uma enorme quantidade de mitos e de novas utopias».

b. Face à necessidade de formar quadros humanos que tendencialmente possam tornar-se autónomos, existem soluções que podem ser aplicadas em espaços culturalmente diferentes. Em África, as lideranças assumem diversas formas que devem ser adaptadas ao contexto.

c. A possibilidade de criação de redes de assistência à saúde pode ser um caminho muito útil e pragmático no desenvolvimento de meios mais interventivos e próximos da população.

d. Quanto aos direitos humanos, onde eles são deturpados, onde, não obstante as constituições serem portadoras de inovação para estes países, estamos longe de os cumprir, malgrado os imensos eventos, fóruns, congressos, que, como escreve Mia Couto, quase nunca levam a nada.

\section{BIBLIOGRAFIA}

Bento XVI (2009). Carta Encíclica Caritas in Veritas. Em htpp// vatican.va/content/benedict-xvi/pt/encyclicals/documents/hf_benxvi_enc_20090629_caritas-in-veritate.html

Campos, L., Portugal, R., Borges, M. (2009), Governação dos Hospitais, Casa das Letras, Alfragide.

Chiavenato, I. (1992), Recursos Humanos - Edição Compacta, São Paulo: edição Atlas.

Conselho Económico e Social das Nações - Comissão Económica para África (2011), Adis Abeba, Etiópia, 24-27 de Março. 
Cruz, C. (2009), Balanced Scorecard - Concentrar uma organização no que é essencial; Porto: Editora Vida Económica.

Escoval, A. (2010). "Contratualização na saúde", Revista Portuguesa de Saúde Pública, Volume Temático: 9.

Grodin, M. (2008), "The Human Right to Health. Law and ethics in rationing access to care in a high-cost global economy" - 2nd Bienal Seminar in Health Law and Bioetics. Lisboa: Wendy K. Mariner, Paula Lobato Faria.

Lipovetsky, Gilles et al (2010), A Cultura-Mundo - Resposta a uma Sociedade desorientada, Lisboa: Edições 70, pp.55.

Martins, J. F. (2011), Manual de Cooperação para o Desenvolvimento. Instituto Nacional de Administração (INA) - Oeiras, Portugal.

Mendes, E. (2007), Rede de Promoção da Saúde. Rede social para a organização da promoção da saúde, da integralidade e da Estratégia Saúde da Família, São Paulo, Brasil. Em htpp://promoversaude.ning.com

Monteiro, A. (1996), O Programa de Ajustamento Estrutural na GuinéBissau, Bissau: Instituto Nacional de Estudos e Pesquisa.

OMS (2006), Relatório Mundial da Saúde. Pp. 127-128.

Platão (1970). Diálogos: Protágoras (V), Edições Melhoramentos, São Paulo, p.232.

PNUD (2013), Rapport National sur le Développement Humain.

Rodrigues, L. et al (2011), Manual de Cooperação para o Desenvolvimento, Oeiras: INA-Editora.

Rodrigues, L. (2011), "As Pessoas e suas Comunidades", Manual de Cooperação para o Desenvolvimento, Rodrigues et al. (org.), Oeiras: INA Editora.

Ruger, J. (2011), "Shared Health Gouvernance". The American Journal of Bioethics, ii (7).

Teixeira, S. (2012), Gestão das Organizações, 7. a edição, Lisboa.

Vaz, A. (2009), "Os Serviços não Clínicos no Apoio à Governação", Governação dos Hospitais, Alfragide: Casa das Letras. 